\title{
Mangrove response to attack by a root boring isopod: root repair versus architectural modification
}

\author{
Robert Allen Brooks*, Susan S. Bell \\ Department of Biology, University of South Florida, 4202 E. Fowler Avenue, Tampa, Florida 33620-5200, USA
}

\begin{abstract}
The nature of the plant-animal interaction between wood-boring isopods and the red mangrove Rhizophora mangle L. has been controversial, with discussion ranging from the damage caused by the isopod being detrimental to beneficial for the mangroves they attack. Initiation of lateral roots by the mangrove in response to isopod burrowing has been one of the most commonly cited examples as support for the concept of beneficial herbivory. In this study, the possibility of root repair as a response of Rhizophora to burrowing by Sphaeroma terebrans Bate was evaluated. Previously burrowed prop roots were tagged in the field and the fate of all burrows followed over 14 wk at a site in Upper Tampa Bay, Florida. Results demonstrated that the most common response of the mangrove was to repair abandoned isopod burrows, with $99 \%$ of all tagged roots and $66 \%$ of all monitored burrows showing signs of repair. Lateral root production occurred at a lower frequency (32\% of roots). Similarly, transect surveys performed in Upper Tampa Bay and 2 additional locations (Anna Maria Island and Weedon Island) indicated a high incidence (57 to $82 \%$ ) of attacked aerial roots showing signs of burrow repair. Again, lateral root production was less commonly noted on transects (13 to $25 \%$ of the roots surveyed). Initiation of lateral roots and burrow repair were not mutually exclusive responses and all instances of lateral root production were in conjunction with repair. Our results demonstrate that the most common response to damage is the replacement of root tissue rather than the stimulation of new tissue production.
\end{abstract}

KEY WORDS: Beneficial herbivory $\cdot$ Florida $\cdot$ Isopod $\cdot$ Mangrove $\cdot$ Plant-animal interaction $\cdot$ Prop root · Repair $\cdot$ Rhizophora mangle $\cdot$ Sphaeroma terebrans $\cdot$ Tolerance $\cdot$ Wood borer

\section{INTRODUCTION}

Plant response to herbivore attack has been a topic of contemporary interest, especially in terrestrial systems (Rosenthal \& Kotanen 1994, Strauss \& Agrawal 1999) including agricultural settings (e.g. Rosenthal \& Welter 1995). Two basic types of plant response strategies to herbivores have been postulated: (1) avoidance, which includes escape in space/time or via defense (e.g., chemical or structural) and (2) tolerance (Rosenthal \& Kotanen 1994). Tolerance is defined as tissue repair and regrowth that will require additional energy expenditure (Belsky et al. 1993). Tolerance as a

*E-mail: rbrooks@chuma.cas.usf.edu response allows for the minimization of damage and is predicted to occur when other defenses would either be ineffective or too costly (Strauss \& Agrawal 1999). The degree of tolerance is often referred to as compensation (Strauss \& Agrawal 1999). Conditions which can affect a plant's ability to tolerate herbivory include extrinsic factors such as competition, season, resource/ nutrient limitations, and revisitation by herbivores, along with intrinsic factors such as phenological stage, growth rate, storage capacity, developmental plasticity, ability to shunt energy, the presence of dormant meristems, and nutrient uptake capabilities (Belsky et al. 1993, Rosenthal \& Kotanen 1994). In highly favorable conditions, such as high nutrients or low herbivore re-encounter rates, some experimental evidence suggests that tolerance to herbivory exceeds compen- 
sation (i.e. repair and regrowth of tissue) for loss due to herbivory, leading to an overcompensation in production. In these latter cases, the plant-animal interaction is considered 'beneficial herbivory' or 'overcompensation' (sensu Paige \& Whitham 1987, Paige 1992, 1999, Lennartsson et al. 1998, Agrawal 2000). The 2 herbivore response strategies (i.e. avoidance and tolerance) may not be mutually exclusive, however, and some species may demonstrate levels of both (Fineblum \& Rausher 1995, Mauricio et al. 1997).

The red mangrove Rhizophora mangle L. produces aerial prop roots from the bole, trunk, and other aboveground roots which grow down through the water column and eventually attach to the substratum (Gill \& Tomlinson 1977). The aerial portion of these prop roots has secondary vascular development and thick surface cells that are not found in the subterranean part of the root once it attaches (Gill \& Tomlinson 1975). Worldwide, the wood boring isopod Sphaeroma terebrans Bate exploits the intertidal habitat created by prop roots in the fringing red mangrove (Rehm \& Humm 1973, Estevez 1978). The relationship between $S$. terebrans and the red mangrove is not strictly herbivorous as $S$. terebrans does not ingest the root material but instead creates a burrow for protection and filterfeeding purposes (John 1971). S. terebrans is found almost exclusively within free hanging aerial roots of $R$. mangle (Estevez 1978) and is present only within the intertidal zone. The habitat suitability of a root for isopod colonization is influenced by the root qualities of increased submergence depth and diameter. The complex interplay of these 2 biotic and physical aspects offers a root with a larger submerged surface area an increased probability of being colonized by isopods via either an increased target size in space or a longer window of accessibility in time (Brooks \& Bell 2001). Along a root, there is strong preference by isopods to establish burrows in the root tip (Perry \& Brusca 1989, Ellison \& Farnsworth 1990, Brooks \& Bell 2001).

The relationship of wood-boring isopods (Sphaeromatids) to Rhizophora provides a useful marine system for investigating the topic of plant response. The impact of isopod burrowing has been somewhat controversial, with discussion ranging from the damage caused by the isopod as 'ecocatastrophic' to beneficial for the mangroves they attack (see Olaffson 1998). Isopod burrowing has been documented to reduce root growth rates and increase root tip atrophy/breakage (Ellison \& Farnsworth 1990, 1992, Perry 1998). In contrast, an increase in root production may occur via the initiation of multiple lateral roots near sites of isopod injury (Simberloff et al. 1978). Notably this latter response by the red mangrove to isopod burrowing has been one of the most commonly cited examples as support for the concept of beneficial herbivory (Belsky 1986).
Here we ask: Are red mangroves capable of repairing isopod burrows? If so, is this a common response to isopod burrowing and does burrow repair occur on attacked roots more frequently than lateral root initiation? We then discuss the implications of our findings with respect to the concept of plant response to herbivory.

\section{MATERIALS AND METHODS}

Burrow repair. Prior to monitoring, a sample of roots within the study site were brought back to the laboratory and cross-sections of the roots through locations of present and prior burrowing were made to identify external burrow appearance with any sign of internal repair. Burrows were determined visually to be either intact (Fig. 1A), or in the process of repair with several stages of burrow repair evident (Fig. 1C,E,G). The classification of burrow repair determined in the lab was then used in the field to assess burrow status.

Tagged root study. A field study was conducted, commencing April 2000, in Mobbly Bay $\left(28^{\circ} 01^{\prime} \mathrm{N}\right.$, $82^{\circ} 39^{\prime} \mathrm{W}$ ) located in the northern part of Tampa Bay, Florida. Isopods occupy $85 \%$ of the aerial roots along the mangrove fringe within this site. Occupied roots normally have between 4 and 8 burrows. This level of attack by Sphaeroma terebrans on mangroves found at the mangrove/salt marsh ecotone in the Tampa Bay region is at the high end of the range for that of mangrove-boring sphaeromids from more tropical regions (Brooks \& Bell 2001).

To determine the ability of Rhizophora mangle to repair damage by Sphaeroma terebrans, 56 unattached aerial roots with visible signs of isopod burrows along the seaward fringe were haphazardly selected for study. Only 1 root per individual tree was used. These roots were tagged and all burrows on the roots were mapped. The fates of these burrows were then monitored at 8,12 , and 14 wk after tagging. Burrows which were absent at subsequent samplings were considered to be completely repaired during the sampling interval. Any newly initiated burrows which appeared during the study interval were also recorded and monitored. Measurements of root growth rate $\left(\mathrm{mm} \mathrm{d}^{-1}\right)$ and initiation of lateral roots (number $\operatorname{root}^{-1}$ ) were also recorded.

Transect surveys in additional sites. Surveys of burrow repair were also conducted at 2 additional locations within the Tampa Bay area, Weedon Island $\left(27^{\circ} 56^{\prime} \mathrm{N}, 82^{\circ} 36^{\prime} \mathrm{W}\right)$ and Anna Maria Island $\left(27^{\circ} 30^{\prime} \mathrm{N}\right.$, $82^{\circ} 43^{\prime} \mathrm{W}$ ), to quantify burrow repair at other locations. Within all study sites, four $25 \mathrm{~m}$ transects were established along the seaward mangrove fringe and roots were sampled at $1 \mathrm{~m}$ intervals along the transect $\left(n=100\right.$ roots $\left.\operatorname{site}^{-1}\right)$. At each meter mark, the closest 

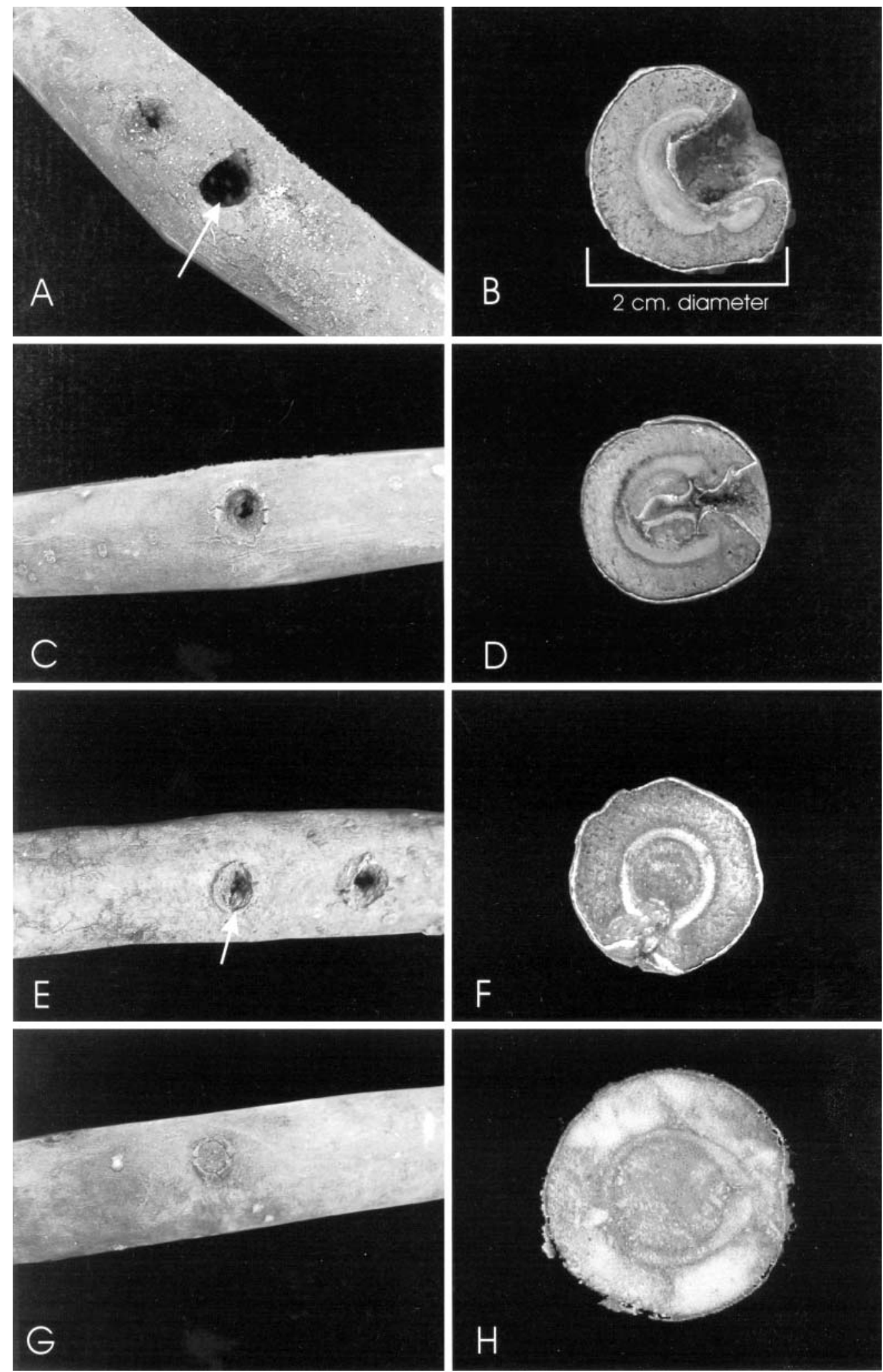

Fig. 1. Whole root and corresponding cross-sectional view of red mangrove aerial roots showing damage to stele and sequence of isopod burrow repair. Arrows indicate which of the multiple burrows is shown in cross-section. (A-B) Non-repairing burrow with isopod removed; $(\mathrm{C}-\mathrm{D})$ and $(\mathrm{E}-\mathrm{F})$ unoccupied burrows in the process of repair; $(\mathrm{G}-\mathrm{H})$ unoccupied burrow approaching complete repair 
Table 1. Incidence of repair and lateral root production found along transects within each study site (n $=25$ roots sampled per transect)

\begin{tabular}{|lccc|}
\hline Site & $\begin{array}{c}\text { Mean (SE) percentage } \\
\text { of roots showing repair } \\
\text { per transect }\end{array}$ & $\begin{array}{c}\text { Mean (SE) percentage } \\
\text { of total burrows } \\
\text { showing repair }\end{array}$ & $\begin{array}{c}\text { Mean (SE) percentage of } \\
\text { roots showing lateral root } \\
\text { production per transect }\end{array}$ \\
\hline Mobbly Bay & $82(5.0)$ & $40(3.2)$ & $25(3.4)$ \\
Weedon Island & $72(2.8)$ & $38(3.3)$ & $21(2.5)$ \\
Anna Maria Island & $57(3.0)$ & $46(4.4)$ & $13(1.0)$ \\
\hline
\end{tabular}

aerial root with isopod damage was selected for examination. The number of isopod burrows and lateral roots, as well as indications of burrow repair, were recorded for each sampled root.

Data analyses. To determine any effects of isopod burrowing on root growth, linear regression was performed. In the regression, the amount of root growth over the study period was used as the dependent variable and the number of burrows the root contained throughout the study period was used as the independent variable. First, regression analysis was performed including all of the roots; additional analyses were performed for roots with and without lateral roots separately. $T$-tests were performed to evaluate any significant differences in the frequency of repair versus initiation of lateral roots for the transect surveys. A Spearman rank order correlation test was performed to determine any relationship between the initiation of lateral roots and the number of isopod burrows along the root. Additionally, a Mann-Whitney rank sum test was used to determine any significant differences in the frequency of repair on roots which remained unattached to the sediment during the study interval versus those which became grounded during the $14 \mathrm{wk}$.

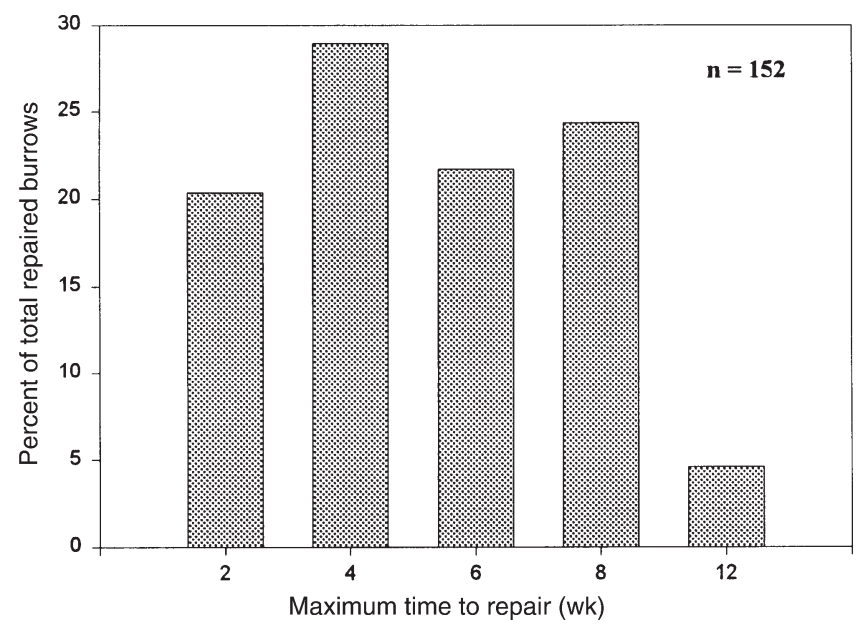

Fig. 2. Frequency distribution for maximum time of burrow repair for those burrows which were found to completely repair during sequential monitoring

\section{RESULTS AND DISCUSSION}

A total of 438 burrows on tagged roots were monitored in Mobbly Bay, of which $62 \%$ were either completely repaired beyond visible recognition (i.e. no scars) or in various stages of repair over the $14 \mathrm{wk}$ period (Fig. 1). Repair of isopod damage (Fig. 1B,D,F,H) was found in all but 1 of the 56 roots monitored at Mobbly Bay. Moreover, the incidence of burrow repair on roots was common along transects at Mobbly Bay, Weedon Island, and Anna Maria Island (Table 1). Similar levels of burrow repair were noted among all 3 sites, with 38 to $46 \%$ of all burrows inspected showing signs of repair (Table 1). These results suggest that mangroves may use the response strategy of tolerance against damage from isopods via tissue regrowth and replacement once burrows are abandoned by the isopod. One could argue that a tolerance strategy would not be predicted of a plant, such as the mangrove, which is a slow growing dicot in a resource-limited environment (Rosenthal \& Kotanen 1994). Information from Boto \& Wellington (1983) show mangroves in the lower intertidal can be nitrogen limited and that might be the case here as well.

By following root growth rate, burrow location, and burrow status over time we were able to quantify the dynamic nature of burrow occurrence. Once trees began burrow repair, the time required for completion (i.e. beyond visible recognition of burrow identification) ranged from $<2$ to $>12 \mathrm{wk}$ (Fig. 2). The average repair time was between 4 and $6 \mathrm{wk}$. Thus, the majority of the burrows were repaired within 1 to 2 mo. The time for burrow repair was not related to root growth rate as burrows from the same root may display highly variable times to complete repair (e.g. 2 to $12 \mathrm{wk}$ ). The rapidity of complete repair from damage may explain why repair has not previously been noted in studies of isopod attack. Thus, design of an appropriate sampling scheme for determining isopod attack rates must consider the possible rapid disappearance of burrows, once abandoned.

Sites of repair along the root varied greatly as repairing burrows were recorded 0 to $50 \mathrm{~cm}$ away from the root tip. As in previous studies, roots with isopod burrows present had reduced growth rates (Perry 1988, 
Ellison \& Farnsworth 1990, 1992), and we found a negative relationship between the total number of (intact) burrows $\left(\mathrm{n} \times \operatorname{root}^{-1} \times 14 \mathrm{wk}^{-1}\right)$ and root growth rate $\left(\mathrm{r}^{2}=0.11, \mathrm{p}=0.05\right.$; linear regression) for roots without laterals (Fig. 3). Burrow repair therefore should have a positive impact upon future root growth rates by decreasing the number of burrows and presumably reducing osmotic stress and fungal/pathogen attack (Wier et al. 1996). The presence of lateral roots resulted in a similar reduction in the root growth rate regardless of the amount of isopod burrowing (Fig. 3). Thus, the presence of lateral roots masked any change in root growth related to the number of isopod burrows present and regression analysis indicated a significant difference in slope of the growth rate for roots which initiated laterals compared to those that did not ( $\mathrm{p}<$ 0.05; $t$-test for slope comparison, Zar 1996).

Lateral branches initiated on the marked roots at Mobbly Bay occurred at a lower frequency (32\%) than that of roots with burrow repair (98\%). Based upon the transect data (Table 1) incidence of repair was also significantly higher than lateral root initiation for all sites $(p<0.001 ; t$ test). The evaluation of whether burrow repair is a more common response than lateral root initiation is, in fact, a conservative estimate. Note root repair was found to occur substantially more frequently than lateral root initiation, assuming that $100 \%$ of the lateral roots were initiated in response to burrowing. Past studies have found that lateral root production does not occur or is extremely rare unless triggered by injury (Gill \& Tomlinson 1977 , Perry \& Brusca 1989). However, if not all lateral roots were produced as a result of burrowing, mangrove response to attack via burrow repair is even more biased toward burrow repair than lateral root initiation.

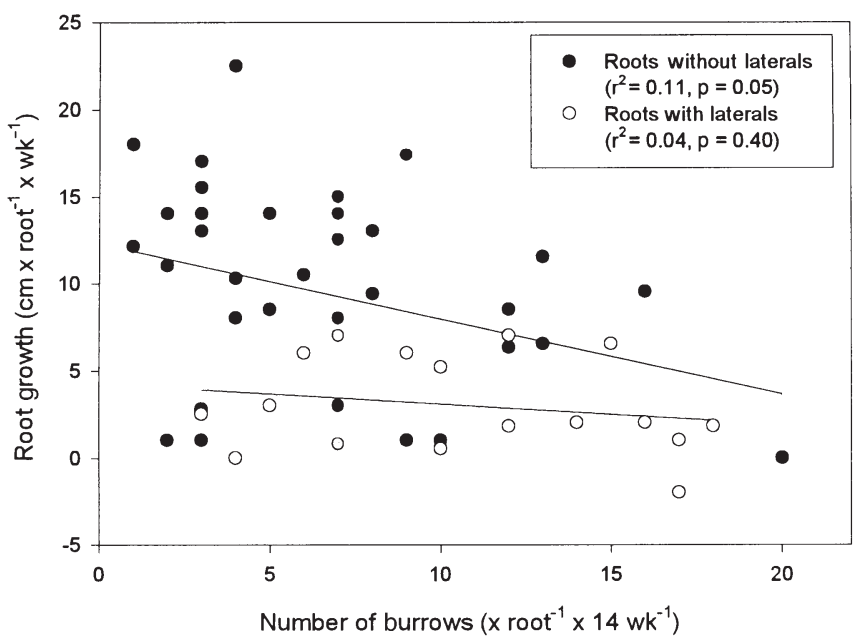

Fig. 3. Linear regression of root growth rate on the number of Sphaeroma terebrans burrows along a root. (o) Roots that initiated lateral roots; $(\bullet)$ roots that did not
Initiation of lateral roots and burrow repair were not mutually exclusive responses, however, as both tolerance response strategies could be found along the same root. In the one instance where burrow repair was not found to occur, no lateral roots were initiated either. Thus, all lateral root initiation was in conjunction with repair and was correlated with the number of isopod burrows along the root $(r=0.30, p=0.02$, Spearman rank order correlation).

Sphaeroma terebrans is found almost exclusively within unattached aerial roots but these aerial roots, when grounded to the substratum (i.e. 'attached'), almost never display signs of isopod attack (Estevez 1978, Perry 1988, Perry \& Brusca 1989). How attached roots avoid isopod attack and/or why they exhibit little sign of attack has yet to be adequately addressed. Predation by benthic predators or secondary thickening of the root after attachment are 2 mechanisms offered to explain the lack of isopod attack (Perry 1988). The results of our tagged root study demonstrate that attacked roots can reach the substratum and subsequently become attached as 13 of the 56 roots at Mobbly Bay became grounded over the 14 wk study interval. Moreover, the frequency of burrow repair in the newly attached roots was significantly greater than that of roots which did not reach the substrate (Fig. 4, Mann-Whitney rank sum test; $\mathrm{p}<0.001$ ). In addition, burrow repair in attached roots was noted before any changes (i.e. secondary thickening) in external anatomy occurred. Our findings demonstrate that the lack of burrows on attached roots does not preclude the possibility of prior isopod attack and suggest that isopod abandonment of burrows may be increased once roots reach the sediment substratum. Thus, the red

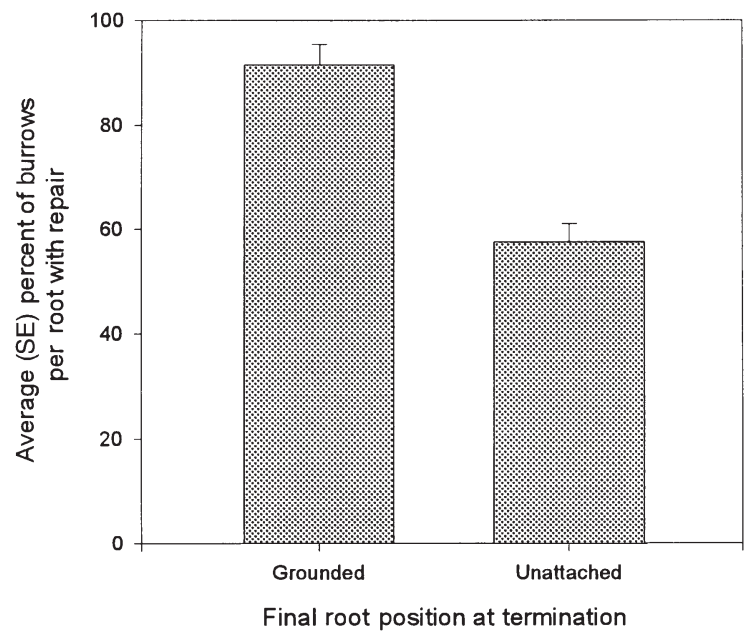

Fig. 4. Percent of repaired burrows (mean $\pm 1 \mathrm{SE}$ ) on aerial roots that reached the substratum during the course of the study versus those that did not 
mangrove may be exhibiting 2 different strategies set apart temporally such that a tolerance strategy is displayed in response to damage, while the roots are still unattached but an avoidance strategy appears to be adopted once the root becomes attached to the substratum. Avoidance by isopods for attached roots does not appear in this study to be linked to either initial secondary thickening upon penetration of the substrate or predation based upon the results of Brooks \& Bell (2001). Additionally, since the wood is not actually ingested by $S$. terebrans, chemical defenses (e.g. tannin concentration) would probably have a limited role in this system (Rotramel 1975, Cragg et al. 1999).

In conclusion, mangrove response to isopod damage by shunting energy to new material (lateral roots) is but one possible response to damage by isopod burrows. We present new evidence that mangroves replace root structure (i.e. repair) and that this is a more common response than lateral root initiation at our study sites. Given that burrows negatively affect root growth and repair represents an energetic cost to the mangrove tree, the categorization of the Sphaeroma terebrans-Rhizophora mangle relationship as one of beneficial herbivory (Belsky 1986) may need to be reconsidered. However, if a root compensates for damage by both repairing burrows and initiating lateral roots with production exceeding that lost due to a reduced root growth rate, then support may still exist for beneficial herbivory.

Acknowledgements. G. Fox, E. Estevez, and 3 anonymous reviewers made many helpful comments on earlier drafts of the manuscript. N. Gassien provided field assistance. This work was supported in part by an Aylesworth Fellowship and Old Salt Fishing Organization Fellowship to R.A.B.

\section{LITERATURE CITED}

Agrawal AA (2000) Overcompensation of plants in response to herbivory and the by-product benefits of mutualism. Trends Plant Sci 5:309-313

Belsky AJ (1986) Does herbivory benefit plants? A review of the evidence. Am Nat 127:870-892

Belsky AJ, Carson WP, Jensen CL, Fox GA (1993) Overcompensation by plants: herbivore optimization or red herring? Evol Ecol 7:109-121

Boto KG, Morris JT (1984) Soil characteristics and nutrient status in a northern Australian mangrove forest. Estuaries 71:61-69

Boto KG, Wellington JT (1983) Phosphorus and nitrogen nutritional status of a Northern Australian mangrove forest. Mar Ecol Prog Ser 11:63-69

Brooks RA, Bell SS (2001) Colonization of a dynamic substrate: factors influencing recruitment of the wood boring isopod, Sphaeroma terebrans, onto red mangrove (Rhizophora mangle) prop roots. Oecologia 127:522-532

Cragg SM, Pitman AJ, Henderson SM (1999) Developments in the understanding of the biology of marine wood boring crustaceans and in methods of controlling them. Int Biodeterior Biodegrad 43:197-205

Editorial responsibility: Lisa Levin (Contributing Editor), La Jolla, California, USA
Ellison AM, Farnsworth EJ (1990) The ecology of Belizean mangrove-root fouling communities: I. Epibenthic fauna are barriers to isopod attack of red mangrove roots. J Exp Mar Biol Ecol 142:91-104

Ellison AM, Farnsworth EJ (1992) The ecology of Belizean mangrove-root fouling communities; patterns of epibiont distribution and abundance, and effects on root growth. Hydrobiologia 247:87-98

Estevez ED (1978) Ecology of Sphaeroma terebrans Bate, a wood boring isopod, in a Florida mangrove forest. PhD dissertation, University of South Florida, Tampa, FL

Fineblum WL, Rausher MD (1995) Tradeoff between resistance and tolerance to herbivore damage in a morning glory. Nature 377:517-520

Gill AM, Tomlinson PB (1975) Aerial roots: an array of forms and functions. In: Torrey JG, Clarkson DT (eds) The development and function of roots. Academic Press, New York, p $237-260$

Gill AM, Tomlinson PB (1977) Studies on the growth of red mangrove (Rhizophora mangle L.) 4. The adult root system. Biotropica 9:145-155

John PA (1971) Reaction of Sphaeroma terebrans Bate to other sedentary organisms infesting the wood. Zool Anz 186:126-136

Lennartsson T, Nilsson P, Tuomi J (1998) Induction of overcompensation in the field gentian, Gentianella campestris. Ecology 79:1061-1072

Mauricio R, Rausher MD, Burdick DS (1997) Variation in the defense strategies of plants: are resistance and tolerance mutually exclusive? Ecology 78:1301-1311

Olafsson E (1998) Are wood-boring isopods a real threat to the well being of mangrove forests? Ambio 27:760-761

Paige KN (1992) Overcompensation in response to mammalian herbivory: from mutualistic to antagonistic interactions. Ecology 73:2076-2085

Paige KN (1999) Regrowth following ungulate herbivory in Ipomopsis aggregata geographic evidence for overcompensation. Oecologia 118:316-323

Paige KN, Whitham TG (1987) Overcompensation in response to herbivory: the advantage of being eaten. Am Nat 129: $407-416$

Perry DM (1988) Effects of associated fauna on growth and productivity in the red mangrove. Ecology 69:1064-1075

Perry DM, Brusca RC (1989) Effects of the root boring isopod Sphaeroma peruvianum on red mangrove forests. Mar Ecol Prog Ser 57:287-292

Rehm A, Humm HJ (1973) Sphaeroma terebrans: a threat to the mangroves of Southwest Florida. Science 182: 173-174

Rosenthal JP, Kotanen PM (1994) Terrestrial plant tolerance to herbivory. Trends Ecol Evol 9:145-148

Rosenthal JP, Welter SC (1995) Tolerance to herbivory by a stemboring caterpillar in architecturally distinct maizes and wild relatives. Oecologia 102:146-155

Rotramel G (1975) Filter-feeding by the marine boring isopod, Sphaeroma quoyanum H. Milne Edwards, 1840 (Isopoda, Sphaeromatidae). Crustaceana 28:7-10

Simberloff D, Brown BJ, Lowrie S (1978) Isopod and insect root borers may benefit Florida mangroves. Science 201: $630-632$

Strauss SK, Agrawal AA (1999) The ecology and evolution of plant tolerance to herbivory. Trends Ecol Evol 14:179-185

Wier AM, Schnitzler MA, Tattar TA, Klekowski EJ Jr, Stern AI (1996) Wound periderm development in red mangrove, Rhizophora mangle L. Int J Plant Sci 157:63-70

Zar JH (1996) Biostatistical analysis, 3rd edn. Prentice-Hall, Englewood Cliffs, NJ

Submitted: May 7, 2001; Accepted: July 11, 2001

Proofs received from author(s): March 1, 2002 